\title{
Rituximab-induced hypogammaglobulinemia in patients with neuromyelitis optica spectrum disorders
}

Andrea Marcinnò, MD, * Fabiana Marnetto, MSc, * Paola Valentino, MSc, Serena Martire, MSc, Alessia Balbo, MLT, Aurora Drago, MSc, Maria Leto, MD, Marco Capobianco, MD, Giancarlo Panzica, PhD, and Antonio Bertolotto, MD

Neurol Neuroimmunol Neuroinflamm 2018;5:e498. doi:10.1212/NXI.0000000000000498

\section{Abstract}

\section{Objective}

To evaluate the long-term effects of rituximab (RTX) on total and specific immunoglobulins (Igs) in patients with neuromyelitis optica spectrum disorders (NMOSDs).

\section{Methods}

Total IgG, IgA, and IgM levels were evaluated in 15 patients with NMOSDs treated with RTX (median follow-up 70 months). Anti-aquaporin 4 (AQP4)-IgG titration was performed on samples from 9 positive patients. Anti-tetanus (TET), anti-varicella-zoster virus (VZV), and anti-Epstein-Barr virus nuclear antigen (EBNA) IgGs were also tested in patients with NMOSDs and in 6 healthy controls (HCs).

\section{Results}

RTX reduced total IgG by $0.42 \mathrm{~g} / \mathrm{L}$ per year, IgA by $0.08 \mathrm{~g} / \mathrm{L}$ per year, and IgM by $0.07 \mathrm{~g} / \mathrm{L}$ per year. Hypogammaglobulinemia (hypo-IgG) $(\mathrm{IgG}<7 \mathrm{~g} / \mathrm{L})$ developed in $11 / 15$ patients. Severe hypo-IgG $(\operatorname{IgG}<4 \mathrm{~g} / \mathrm{L})$ was found in $3 / 15$ patients, of whom 2 patients developed serious infectious complications. In group analysis, anti-AQP4 IgG titers were reduced by RTX over time, and a significant correlation between anti-AQP4 IgG titers and total IgG levels was found. The effects of RTX were observed on pathogen-specific IgGs as well. In particular, the levels of anti-TET IgG in patients were significantly lower than those in HCs. The half-life of anti-TET IgG was reduced by about $50 \%$ in patients compared with the general population.

\section{Conclusions}

Long-term RTX treatment is associated with the risk of hypo-Ig and reduction of anti-TET protection in patients with NMOSDs. Results obtained in this study suggest the importance of monitoring total and specific Ig levels before and during treatment with anti-CD20 drugs to prevent hypo-Ig-related complications and to optimize clinical management.

\author{
Correspondence \\ Fabiana Marnetto \\ fabiana.marnetto@gmail.com
}




\section{Glossary}

anti-AQP4 = anti-aquaporin 4; EBNA = Epstein-Barr virus nuclear antigen; $\mathbf{H C}=$ healthy control; hypo-Ig = hypogammaglobulinemia; IFI = immunofluorescence; IVIG = IV immunoglobulin; LMM = linear mixed model; NMOSD = neuromyelitis optica spectrum disorder; PLEX = plasma exchange course; $\mathbf{R T X}=$ rituximab; TET = tetanus; VZV = varicella-zoster virus.

Rituximab (RTX) is a monoclonal antibody that recognizes the CD20 antigen expressed on B lymphocytes. Its mechanism of action involves B-cell cytotoxicity through various pathways. ${ }^{1,2}$ After more than 2 decades of use, RTX is widely prescribed not just in the treatment of non-Hodgkin lymphomas, ${ }^{3}$ in which it was first approved, but for a variety of autoimmune diseases wherein depletion of circulating $\mathrm{CD} 20^{+}$ $\mathrm{B}$ cells is the common therapeutic goal. ${ }^{4-9}$ It is also an effective, yet off-label treatment for neuromyelitis optica spectrum disorders (NMOSDs), ${ }^{10,11}$ a group of inflammatory immune-mediated demyelinating disorders of the CNS. ${ }^{12,13}$ Ample evidence exists for major side effects including hypogammaglobulinemia (hypo-Ig) after a prolonged treatment with RTX in patients with rheumatologic ${ }^{14-16}$ diseases (table e-1, links.lww.com/NXI/A70). However, in NMOSDs, the evaluation of hypo-Ig as a side effect of RTX treatment has seldom been the focus of the available studies till date (table e-2, links.lww.com/NXI/A71). A recent study focused on infectious complications associated with hypo-Ig in 5 patients with NMOSDs treated with RTX. ${ }^{17}$ In view of the treatment duration of RTX along with new anti-CD20 therapies with extensive neurologic use (e.g. in MS), ${ }^{18}$ it is vital for the clinicians to recognize and manage the safety concerns and side effects of this drug. Thus, we sought to characterize the qualitative and quantitative changes in humoral immunity in patients with NMOSDs during a sustained RTX therapy through the evaluation of total IgG, IgA, and IgM levels, anti-aquaporin 4 (anti-AQP4) IgG levels, and of levels of 3 pathogen-specific antibodies. Key strengths of our study are a long follow-up period, systematic measurements, and a relatively large number of patients under study.

\section{Methods}

\section{Patients and healthy controls}

This is an observational retrospective case series study, in which serum levels of total IgG, IgA, IgM, and specific IgGs namely anti-tetanus (TET), varicella-zoster virus (VZV), and Epstein-Barr virus nuclear antigen (EBNA) were evaluated in 15 patients with NMOSDs undergoing long-term RTX treatment. This specific humoral immunity was evaluated in 6 healthy controls (HCs) as well.

Patients were followed up at the Regional Reference Centre for Multiple Sclerosis (CReSM) at Orbassano (Turin, Italy). The demographic and clinical ${ }^{19-22}$ details of the patients have been described in table 1 .
All patients were treated with RTX and monitored monthly according to a treatment-to-target approach, where RTX reinfusions were given whenever the percentage of CD19+B cells was more than $0.1 \%$ in peripheral blood mononuclear cells. The details of RTX therapy and of other treatments given to patients before or during RTX treatment have been described in table 1 . Treatment regimens during clinical relapses included IV methylprednisolone $(1000 \mathrm{mg}$ for 5 consecutive days without tapering) and/or plasma exchange courses (PLEX) performed in 3-7 plasmapheresis procedures every other day for each course or intravenous immunoglobulin (IVIG) infusions $(0.4 \mathrm{~g} / \mathrm{kg}$ for 5 consecutive days for each course).

The median follow-up period of RTX treatment in the present study was 70 (range 17-124) months for a total of 972 person-months of RTX follow-up. Seven patients were followed up for at least 70 months. Ninety-one total RTX infusions were administered (median 4 infusions/patient; range: $2-13$ infusions/patient). The median interval between treatments was 11 (range: 3-36) months.

\section{Samples selection}

A blood sample was collected approximately every 6 (median 6.6; range 5.0-16.5) weeks, following rigorous procedures from blood collection to serum sample storage. A total of 715 serum samples were available, stored at $-80^{\circ} \mathrm{C}$ in the CReSM collection. Of note, 236 samples were tested in the present study.

The following selection criteria for samples were applied: (1) overlap of sample collection time with anti-AQP4 IgG titration when possible; and (2) exclusion of samples collected within 3 months since a PLEX or IVIG course or within 1 month after any immunosuppressive treatment withdrawal (table 1).

\section{Standard protocol approvals, registrations, and patient consents}

All patients provided written informed consent for the use of their collected samples (approval number 12819/2016).

\section{Laboratory assessments}

We performed serologic examinations on 236 samples from 15 patients with NMOSDs. We evaluated total IgG, IgA, and IgM levels in 188/236 samples (median sampling time interval $=4.9$ months, range 3.3-6.2 months). For $84 / 188$ samples (from 7 patients), data on anti-AQP4 IgG titers were available as well. ${ }^{23}$ In addition, in the present study, 37 samples were evaluated for anti-AQP4 IgG titer (median sampling 
Table 1 Demographic and clinical characteristics of patients

\begin{tabular}{|c|c|c|c|c|c|c|c|c|c|c|}
\hline Patient ID & Sex & $\begin{array}{l}\text { Age } \\
\text { at To }\end{array}$ & $\begin{array}{l}\text { Follow- } \\
\text { up mo }\end{array}$ & $\begin{array}{l}\text { Serum } \\
\text { samples }\end{array}$ & Disease & $\begin{array}{l}\text { Auto-Ab } \\
\text { status }\end{array}$ & $\begin{array}{l}\text { RTX } \\
\text { courses }^{b}\end{array}$ & $\begin{array}{l}\text { Follow- } \\
\text { up ARR }\end{array}$ & $\begin{array}{l}\text { Other intercurrent } \\
\text { treatments }{ }^{c}(\mathrm{mo}) \\
\text { or [courses] }\end{array}$ & $\begin{array}{l}\text { Previous treatments } \\
\text { (mo) or [courses] }\end{array}$ \\
\hline 1 & $\mathrm{~F}$ & 38 & 120 & 22 & $\mathrm{NMO}^{\mathrm{d}}$ & AQP4+ & 13 & 0.3 & & PLEX [1] \\
\hline 2 & $\mathrm{~F}$ & 20 & 124 & 21 & RLETM $^{d}$ & AQP4+ & 9 & 0.1 & R-IVIG [3] & IFN (14) \\
\hline 3 & $\mathrm{~F}$ & 60 & 70 & 17 & rLETM $^{d}$ & AQP4+ & 6 & 0 & & PLEX [1] \\
\hline 4 & $\mathrm{~F}$ & 48 & 48 & 13 & $\mathrm{NMO}^{\mathrm{d}}$ & AQP4+ & 4 & 1 & CFX (3), PLEX [3] & MTX (36), AZA (19) \\
\hline 5 & M & 60 & 39 & 8 & $\mathrm{NMO}^{d}$ & AQP4+ & 4 & 0 & & $\begin{array}{l}\text { PLEX [1], PRED (11), } \\
\operatorname{MMF~(60)~}\end{array}$ \\
\hline 6 & $\mathrm{~F}$ & 57 & 83 & 16 & $\mathrm{NMO}^{\mathrm{d}}$ & AQP4+ & 8 & 0 & & $\begin{array}{l}\text { MTX (13), IFN (6), } \\
\text { PLEX [1], GA (3) }\end{array}$ \\
\hline 7 & $\mathrm{~F}$ & 25 & 123 & 20 & $\mathrm{NMO}^{\mathrm{d}}$ & AQP4+ & 10 & 0.2 & PLEX [1], R-IVIG [1] & IVIG [1] \\
\hline 8 & $\mathrm{~F}$ & 21 & 106 & 20 & rLETM $^{d}$ & AQP4- & 10 & 0.8 & IVIG [1] & PLEX [1] \\
\hline 9 & $\mathrm{~F}$ & 50 & 106 & 20 & rLETM $^{d}$ & AQP4- & 10 & 0.2 & & \\
\hline 10 & $\mathrm{~F}$ & 57 & 23 & 6 & $\mathrm{rON}$ & AQP4- & 3 & 0 & & PLEX [1] \\
\hline 11 & $\mathrm{~F}$ & 77 & 24 & 6 & $\mathrm{NMO}^{d}$ & AQP4+ & 4 & 0 & & $\begin{array}{l}\text { PLEX [1], AZA (1), } \\
\text { MMF (4) }\end{array}$ \\
\hline 12 & $\mathrm{~F}$ & 59 & 20 & 5 & $\mathrm{rON}^{\mathrm{d}}$ & MOG+ & 2 & 1.2 & & \\
\hline 13 & M & 23 & 23 & 7 & LETM & AQP4- & 4 & 0 & & \\
\hline 14 & $\mathrm{~F}$ & 36 & 10 & 2 & $\mathrm{NMO}^{\mathrm{d}}$ & AQP4+ & 2 & 0 & & PLEX [1] \\
\hline 15 & $\mathrm{~F}$ & 43 & 17 & 5 & rLETM $^{d}$ & AQP4- & 2 & 2.1 & IVIG[1] & MTX (12) \\
\hline
\end{tabular}

Abbreviations: $A R R=$ annualized relapse rate; $A Z A=$ azathioprine; $C F X=$ cyclophosphamide; GA = glatiramer acetate; IFN = interferon $\beta$-1 $\mathrm{a}$; IVIG = intravenous immunoglobulin; MMF = mycophenolate mofetil; MTX = mitoxantrone; NMO = neuromyelitis optica; NMOSD = neuromyelitis optica spectrum disorder; PLEX = plasma exchange; PRED = oral prednisolone ( $5 \mathrm{mg}$ every other day); rLETM = (recurrent) longitudinally extensive transverse myelitis; R-IVIG = intravenous immunoglobulin replacement therapy; $\mathrm{rON}=$ recurrent optic neuritis; $\mathrm{RTX}=$ rituximab.

Patients not completely matching the 2015 criteria for NMOSD diagnosis (their treatment regimen was the same, given the presence of acute neurologic episodes, suggesting an autoimmune inflammatory disorder at risk of developing relapses and converting to NMOSD ${ }^{19-22}$ ).

a TO: beginning of RTX treatment.

${ }^{\mathrm{b}}$ Initial RTX dose: $375 \mathrm{mg} / \mathrm{m}^{2}$ once a week for 4 weeks; subsequent RTX courses: 1000 mg infused twice, with a two-week interval.

c Only treatments interfering with Ig levels were considered.

d Diagnosis according to 2015 Wingerchuck revised diagnostic criteria. ${ }^{13}$

time interval $=4.5$ months, range 3.0-7.0 months). In the remaining 48/236 samples (median sampling time interval = 13.5 months, range 7-25 months), anti-TET, anti-VZV, and anti-EBNA IgGs were tested. All the pathogen-specific antigens were tested in 12 samples from $6 \mathrm{HCs}$ as well.

\section{Total immunoglobulin levels}

Serum concentrations of IgG, IgM, and IgA were determined in the Laboratory of Humanitas Hospital Gradenigo (Turin, Italy) by turbidimetry (DXC 600, Beckman-Coulter) according to the manufacturer's instructions. The details regarding the detection of Ig levels are shown in table e-3, links. lww.com/NXI/A72. ${ }^{24,25}$

\section{Anti-AQP4 IgG titration}

According to the latest diagnostic guidelines, ${ }^{13,26}$ anti-AQP4 IgG titers were assessed and titrated using a commercial indirect immunofluorescence (IFI) cell-based assay (FA 11281010-50, Euroimmun, Lubeck, Germany), following the manufacturer's instructions.
We used the same procedure as the one used in our previous studies. $^{23,27}$

IFI reactions were analyzed using Nikon Eclipse 90i (Nikon) with a $\times 20$ magnification. Two different operators (F.M. and P.V.), blinded to the sample type, independently evaluated all reactions. Euroimmun kindly provided all the kits.

\section{Anti-pathogen specific IgG detection}

Anti-TET, anti-VZV, and anti-EBNA IgGs were analyzed in the CDC Laboratory (Turin, Italy), by commercial ELISA (SkyLAB $^{\text {TM }} 752$, AXA Diagnostics, Pomezia RM, Italy; Mago 4; Erba, Mannheim, Germany) as per the manufacturer's instructions. The details regarding their quantification are shown in table e-3, links.lww.com/NXI/A72.

\section{Statistical analysis}

Differences of continuous variables between groups were assessed by the unpaired $t$-test or the Kruskall-Wallis test, as appropriate, whereas differences of categorical variables by the 
Fisher exact test. Correlation between continuous variables was assessed by means of the Pearson correlation. Correlation between IgG levels and anti-AQP4 IgG titers was evaluated by a linear regression model. Univariate linear mixed models (LMMs) with time as a fixed effect and patients as random intercepts were performed to investigate the longitudinal effect of RTX treatment on the Ig titer. An LMM with time and group (patient/control) as fixed effects and participants as random intercepts was used to examine the longitudinal changes of anti-TET IgG and to compare them between patients and controls. The anti-TET IgG halflife $(\mathrm{T} 1 / 2)$ of patients was calculated from the coefficient of the fixed effect of time in an LMM run with patients' data only. Anti-TET IgG concentrations were log-transformed to make data conform to normality. $p$ values were obtained by likelihood ratio tests of the full models against the models without the effect of interest. All analyses were run with $\mathrm{R}$ software (r-project.org).

\section{Data availability}

Individual de-identified patient data not published within the article including clinical evaluations, IgG, IgA, and IgM levels, anti-AQP4 IgG titers, and specific anti-pathogen IgG levels will be shared upon request from any qualified investigator.

\section{Results}

\section{Hypo-Ig as an effect of RTX treatment}

\section{Reduction of IgG, IgA, and IgM levels during RTX treatment}

In the present study, the longitudinal effect of RTX treatment on total Ig levels was investigated using univariate LMMs (figure 1).

RTX significantly reduced total IgG by $0.42 \mathrm{~g} / \mathrm{L}$ per year (LMM, $p<0.0001,95 \% \mathrm{CI},-0.49$ to -0.35 ), IgA by $0.08 \mathrm{~g} / \mathrm{L}$ (LMM, $p<0.0001,95 \% \mathrm{CI},-0.09$ to -0.06 ), and IgM by $0.07 \mathrm{~g} / \mathrm{L}$ (LMM, $p<0.0001,95 \% \mathrm{CI},-0.09$ to -0.06 ).

\section{Hypogammaglobulinemia}

In the present study, hypo-IgG (IgG $<7.0 \mathrm{~g} / \mathrm{L})$ was found in $11 / 15(73 \%)$ patients in at least 1 measurement. Notably, in 4/11 patients, hypo-IgG status was present before the start of RTX treatment. Of note, 3/15 (20\%) patients demonstrated severe hypo-IgG $(\operatorname{IgG}<4.0 \mathrm{~g} / \mathrm{L})$ in at least 1 measurement (figure e-1, links.lww.com/NXI/A66).

Hypo-IgA ( $\operatorname{IgA}<0.7 \mathrm{~g} / \mathrm{L})$ was found in 6/15 (40\%) patients. In 2 patients, this deficiency was present before the start of RTX treatment (figure e-2, links.lww.com/NXI/A67).

Hypo-IgM $(\operatorname{IgM}<0.4 \mathrm{~g} / \mathrm{L})$ was found in 9/15 (60\%) patients. In 1 patient, this deficiency was present before the start of RTX treatment. Of note, 2/15 (13\%) patients developed severe hypo-IgM $(\operatorname{IgM}<0.2 \mathrm{~g} / \mathrm{L})$ in at least 1 measurement (figure e-3, links.lww.com/NXI/A68).
The prevalence of hypo-IgG, hypo-IgA, and hypo-IgM, evaluated in patients with a prolonged follow-up period ( $\geq 5$ years, $\mathrm{n}=7$ patients), increased over time during RTX treatment (figure 1, B, D, F).

\section{Correlation between Ig classes}

A strong correlation was found between the IgG class and IgA or IgM concentrations (Pearson correlation; $p<0.0001 ; r=$ 0.51 and $r=0.49$, respectively), whereas IgA and IgM serum concentrations were weakly correlated (Pearson correlation; $p<0.0001 ; r=0.34$ ) (figure e-4, links.lww.com/NXI/A69). Moreover, the occurrence of hypo-IgG was significantly associated with the occurrence of hypo-IgA, $\operatorname{IgM}$, or both (Fisher exact test, $p=0.002$ ).

\section{Infectious complications}

Two patients (\#2 and \# 8) developed infectious complications after 9 and 8 years of RTX treatment ( 8 and 5 RTX infusions), respectively. Total IgG concentration during that period was $3.6 \mathrm{~g} / \mathrm{L}$ and $3.5 \mathrm{~g} / \mathrm{L}$, respectively. In addition, IgM serum concentration of patient 2 decreased to $0.14 \mathrm{~g} / \mathrm{L}$ during the same period. Such low levels are considered as risk factors for bacterial infections. ${ }^{24,25}$ Patient 2 developed pneumonia along with hand, foot, and mouth disease. Consequently, a new treatment regimen, including RTX and monthly IVIG replacement treatment, was required. On the other hand, patient 8 developed multifocal bilateral pyelonephritis, which was treated with wide-spectrum antibiotics. In this case, severe hypo-IgG was present, although not investigated. In fact, in that period, there were scant evidences of RTX-induced hypo-Ig.

\section{IgG levels and anti-AQP4 IgG titer}

In group analysis, anti-AQP4 IgG serum levels showed a significant reduction in annual median titer (Kruskal-Wallis test, $p$ $<0.0001$ ) (figure 2A). In individual analysis, reduction in antiAQP4 IgG titers was not observed in patients 4 and 5, whereas patient 2 became negative for anti-AQP4 IgG during the RTX follow-up period. On exclusion of patients 4 and 5, a strong correlation was found between total IgG levels and anti-AQP4 IgG titers (linear regression model; $p<0.0001$ ) (figure $2 \mathrm{~B}$ ).

\section{Effect of RTX on specific humoral immunity}

Longitudinal effects of RTX on specific humoral immunity were evaluated on 3 pathogen-specific IgGs.

\section{Anti-TET IgG}

Anti-TET IgG levels were found to be below the protection threshold $(\leq 0.1 \mathrm{IU} / \mathrm{mL})$ at the beginning of the follow-up in $4 / 15$ (27\%) patients. In $1 / 15$ (7\%) patients, the concentration of anti-TET IgG decreased below the defined threshold during RTX treatment. By contrast, anti-TET IgG levels were never found to be below the protection threshold in HCs. Anti-TET IgG showed a reduction in 10/15 patients and in 3/ $6 \mathrm{HCs}$ (figure 3A).

Further analyses were conducted on anti-TET IgG, based on the quantitative nature of the measurements. The analyses 
Figure 1 Total IgG, IgA, and IgM levels and hypo-lg prevalence during RTX treatment

A

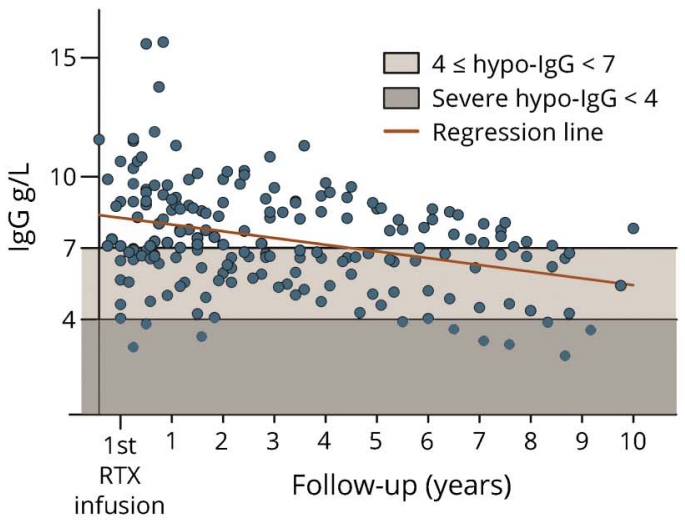

C

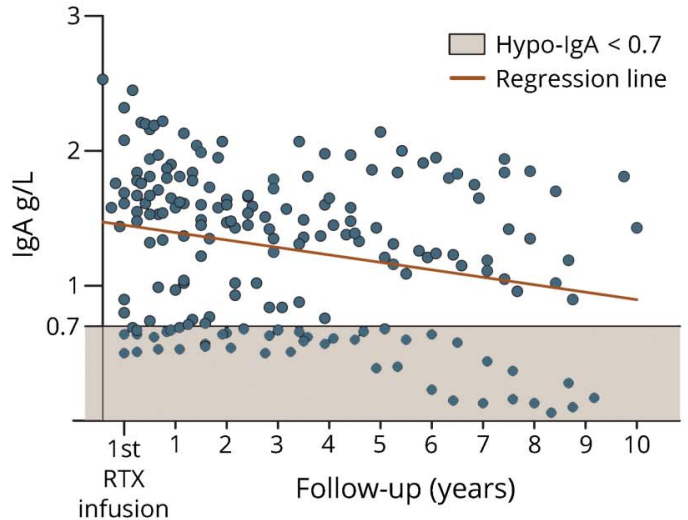

E

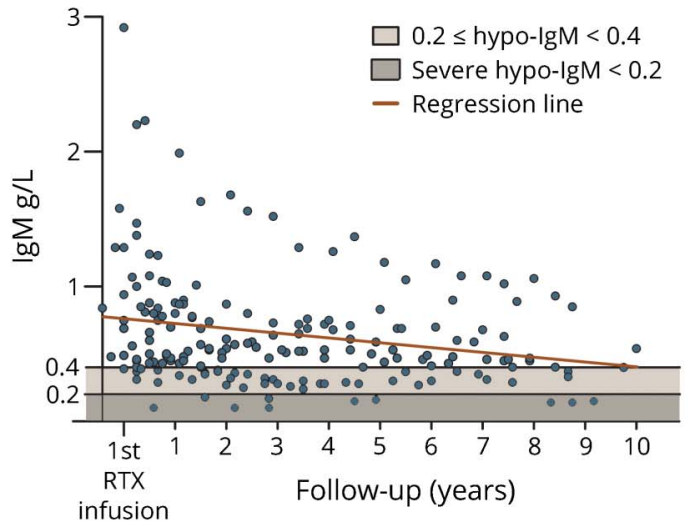

B

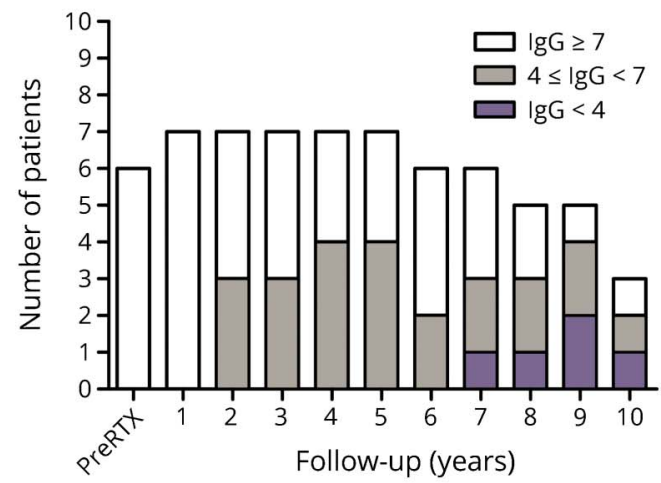

D

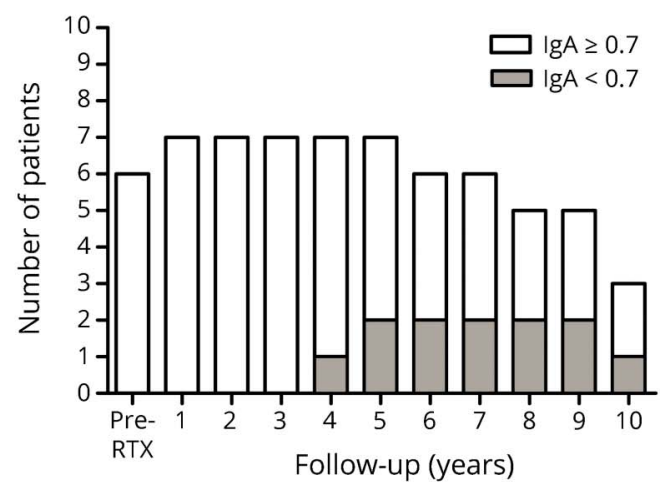

F

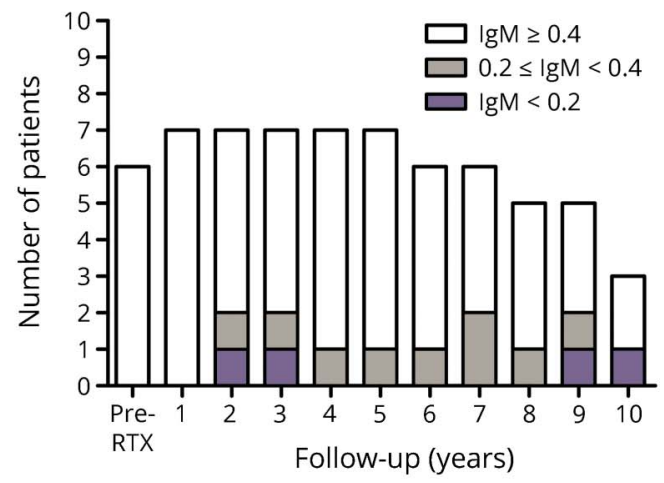

IgG, IgA, and IgM levels were measured in 188 samples from 15 patients with NMOSDs treated with RTX. Median follow-up period was 70 (range 17-124) months. Levels of total IgG, IgA, and IgM in all serum samples are represented in panels A, C, and E, respectively. Black lines represent the thresholds defining hypo-IgG $(<7.0 \mathrm{~g} / \mathrm{L}),-\operatorname{lgA}(<0.7 \mathrm{~g} / \mathrm{L})$, and $-\operatorname{lgM}(<0.4 \mathrm{~g} / \mathrm{L})$. In addition, based on augmented infectious risk, severe hypo-lgG was defined as total IgG levels $<4.0$ g/ $\mathrm{L}$ and severe hypo-IgM as total IgM levels $<0.2 \mathrm{~g} / \mathrm{L}$. Long-term RTX treatment reduced the levels of all Ig classes. Statistical analysis was performed using univariate linear mixed models. Panels B, D, and F show the prevalence of hypo-lg over time according to each specific cutoff. The percentage of patients developing hypo-IgG, hypo-IgA, and hypo-IgM has been calculated in patients with a prolonged follow-up period ( $\geq 5$ years, $n=7$ patients), which showed an increased prevalence over time. In particular, prevalence of patients developing hypo-IgG is represented in panel B: patients developing severe hypo-IgG (IgG $<4 \mathrm{~g} / \mathrm{L}$ ) are represented in purple, as patients showing mild hypo-lgG (5 g/L $\leq \operatorname{lgG}<7 \mathrm{~g} / \mathrm{L}$ ) are represented in gray. Prevalence of patients developing hypo-lgA $(\operatorname{lgA}<0.7 \mathrm{~g} / \mathrm{L})$ is shown in panel $\mathrm{D}$ (gray). Prevalence of patients developing hypo-lgM is shown in panel F: patients developing severe hypo-IgM (IgM $<0.2 \mathrm{~g} / \mathrm{L})$ are represented in purple, as patients showing mild hypo-lgM $(0.2 \mathrm{~g} / \mathrm{L} \leq \operatorname{lgG}<0.4 \mathrm{~g} / \mathrm{L})$ are represented in gray.

were performed after excluding values which showed a doubling of the previous level, thus identifying an anti-TET vaccination recall. ${ }^{28}$
Here, the levels of anti-TET IgG during RTX treatment were found to be significantly lower as compared to HCs (unpaired $t$ test, $p=0.006$ ) (figure 3B). 

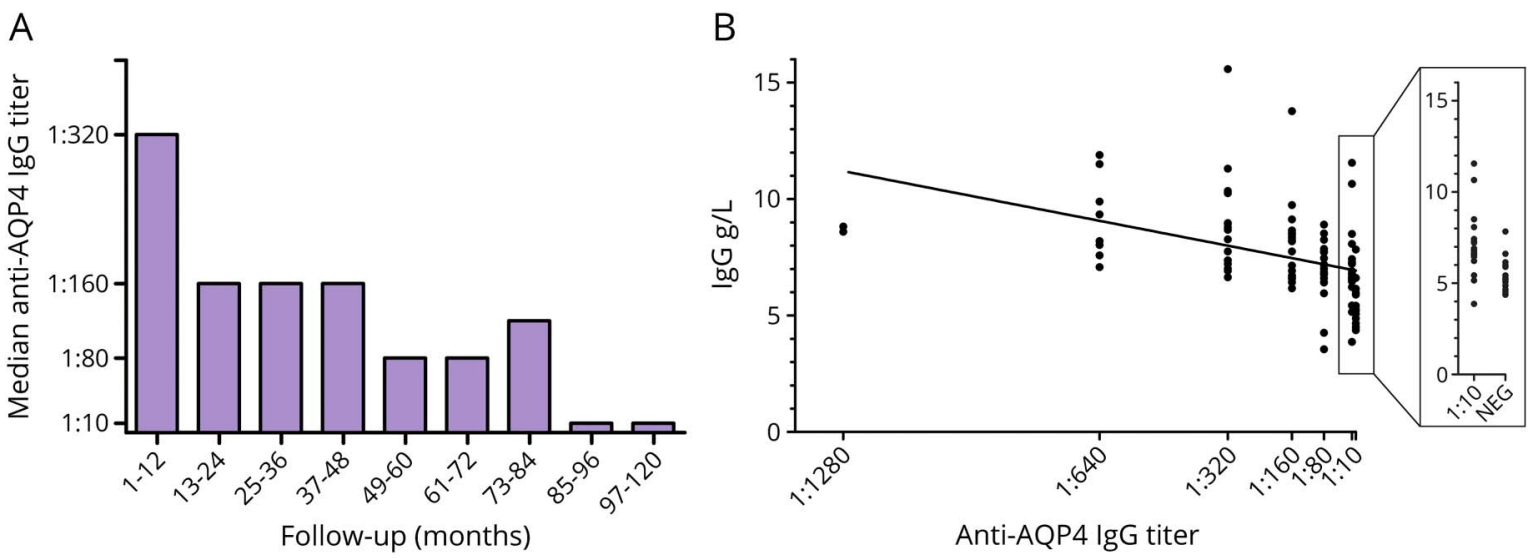

Anti-AQP4 IgG levels were measured in 121 samples from 9 patients positive to AQP4 antibodies. Anti-AQP4 IgG titer decreases during the RTX follow-up period (panel A, Kruskal-Wallis test, $p=0.0001$ ). One of 9 patients (\#2) seroreverted during the follow-up period. A strong correlation between total IgG and anti-AQP4 IgG levels was shown in 7 of 9 patients (panel B; linear regression model, $p<0.0001$ ).

In addition, anti-TET IgG $\mathrm{T} 1 / 2$ in seroprotected patients (anti-TET IgG > $0.1 \mathrm{IU} / \mathrm{mL}$ at beginning of the follow-up period) was 5.52 years (95\% CI: 3.63-10.89), which represents a $50 \%$ reduction compared with the general population. ${ }^{28}$

\section{Anti-VZV and anti-EBNA IgG}

Anti-VZV negativity was found in 1 patient since the beginning of monitoring, whereas another patient developed it during RTX treatment. No individuals from the $\mathrm{HC}$ group showed a negative status. On the other hand, anti-EBNA negativity was found in both $1 \mathrm{HC}$ and 1 patient since the beginning of monitoring.

Anti-VZV and anti-EBNA IgG showed a reduction in $8 / 15$ patients and $0 / 6$ controls and in $12 / 15$ patients and $1 / 6$ controls, respectively (figure $3, \mathrm{C}$ and $\mathrm{D}$ ).

LMMs could not be performed for anti-VZV and anti-EBNA IgG because their levels were expressed as "Index" and not as quantitative concentrations.

\section{Discussion}

There has been a continuous increase in the usage of antiCD20 drugs in the treatment of CNS autoimmune diseases during the past decade. This will be further reinforced by the therapeutic indications of recently approved ocrelizumab for MS. There is a significant proportion of patients with MS and NMOSDs who positively respond to anti-CD20 drugs such as RTX. $^{11,21}$ Thus, it is vital to consider the side effects of these drugs from a wider temporal perspective, given the long-term treatment regimens used in the management of these diseases. RTX has been used "off label” for more than a decade in NMOSDs. The present study evaluates the long-term effects of RTX in patients with NMOSDs on total Ig levels, antiAQP4 IgG levels, and on levels of 3 pathogen-specific IgGs (anti-TET, anti-VZV, and anti-EBNA IgG).
A study published recently in this field has investigated the secondary antibody deficiency as a complication of long-term RTX therapy in patients with NMOSDs. ${ }^{17}$ In comparison, the key strengths of our study include the largest median follow-up period among studies on NMOSDs in addition to sample selection based on strict criteria to reduce the effect of confounding variables. Serum samples used in this study were collected from patients with NMOSDs and stored in the CReSM Collection, following rigorous and consistent procedures.

We observed a significant reduction in total IgG, IgA, and IgM levels in patients with NMOSDs after long-term RTX treatment (figure 1). A strong correlation was observed between the 3 classes (figure e-4, links.lww.com/NXI/A69). Consequently, these changes might stem from a single phenomenon of the sustained depletion of CD20 ${ }^{+} \mathrm{Ig}$ - secreting circulating B cells. These B cells are responsible for a significant portion of immunoglobulin synthesis, ${ }^{29,30}$ as well as for replenishment of plasmablasts and plasma cell compartments. ${ }^{31}$ In our cohort, hypo-IgG occurred in $11 / 15$ patients (73\%), hypo-IgA in $6 / 15$ patients $(40 \%)$, and hypo-IgM in $9 / 15$ patients $(60 \%)$ during treatment. The percentage of hypo-Ig patients increased over time (figure 1). Comparable results have been demonstrated by studies on rheumatic diseases with similar follow-up and RTX dose characteristics ${ }^{14-16}$ (table e-1, links. lww.com/NXI/A70).

Although the group analysis demonstrates a reduction of Igs during RTX treatment, the individual analysis presents disparate Ig concentrations across patients. We then attempted to identify the presence of any association between Ig levels and clinical demographic variables. In patients with at least 2 years of follow-up, no differences in age, IgG baseline levels, or annualized relapse rate were found between patients showing a reduction of $\operatorname{IgG}$ over time and patients showing a stable level of IgG during follow-up (data not shown). 

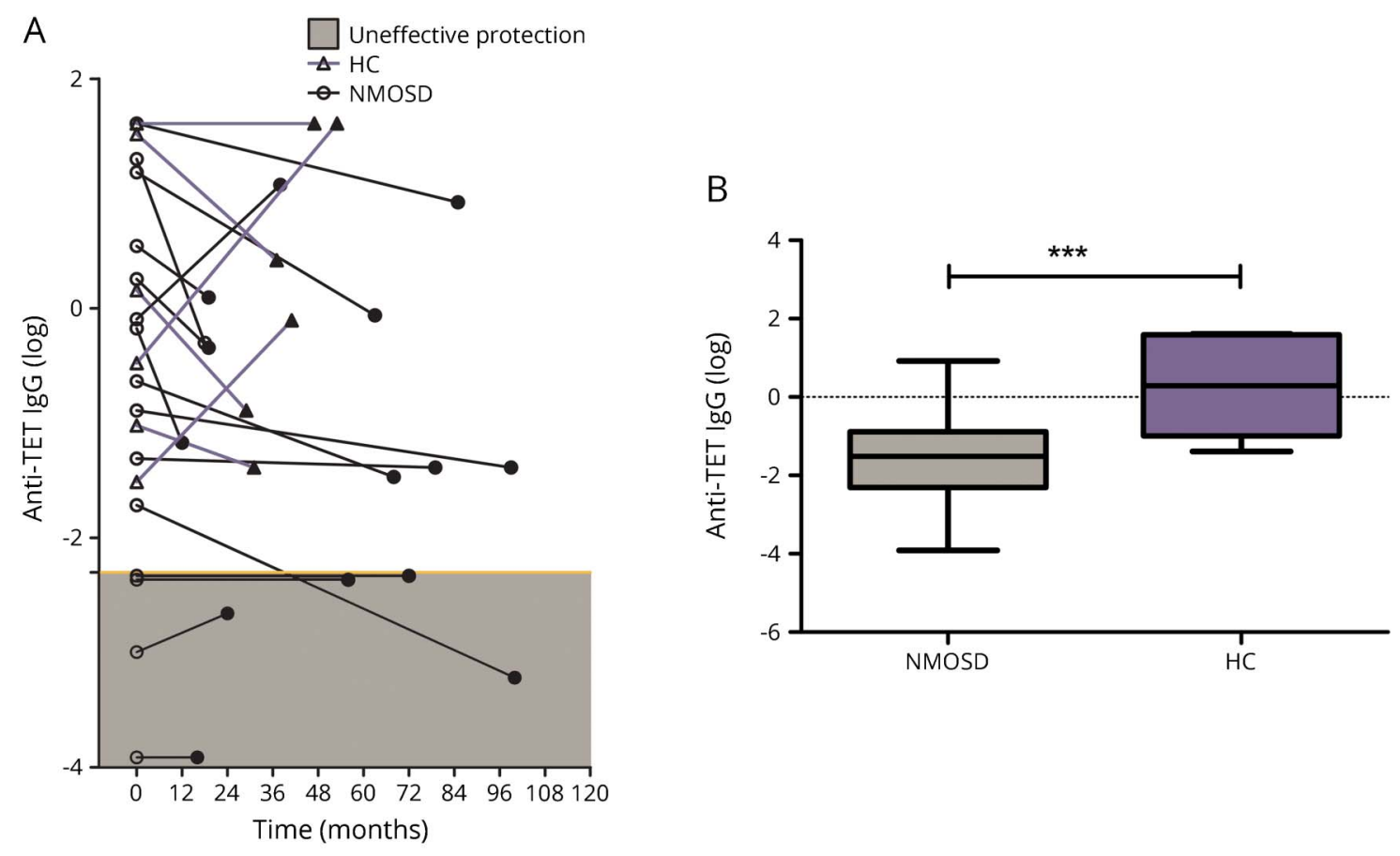

C
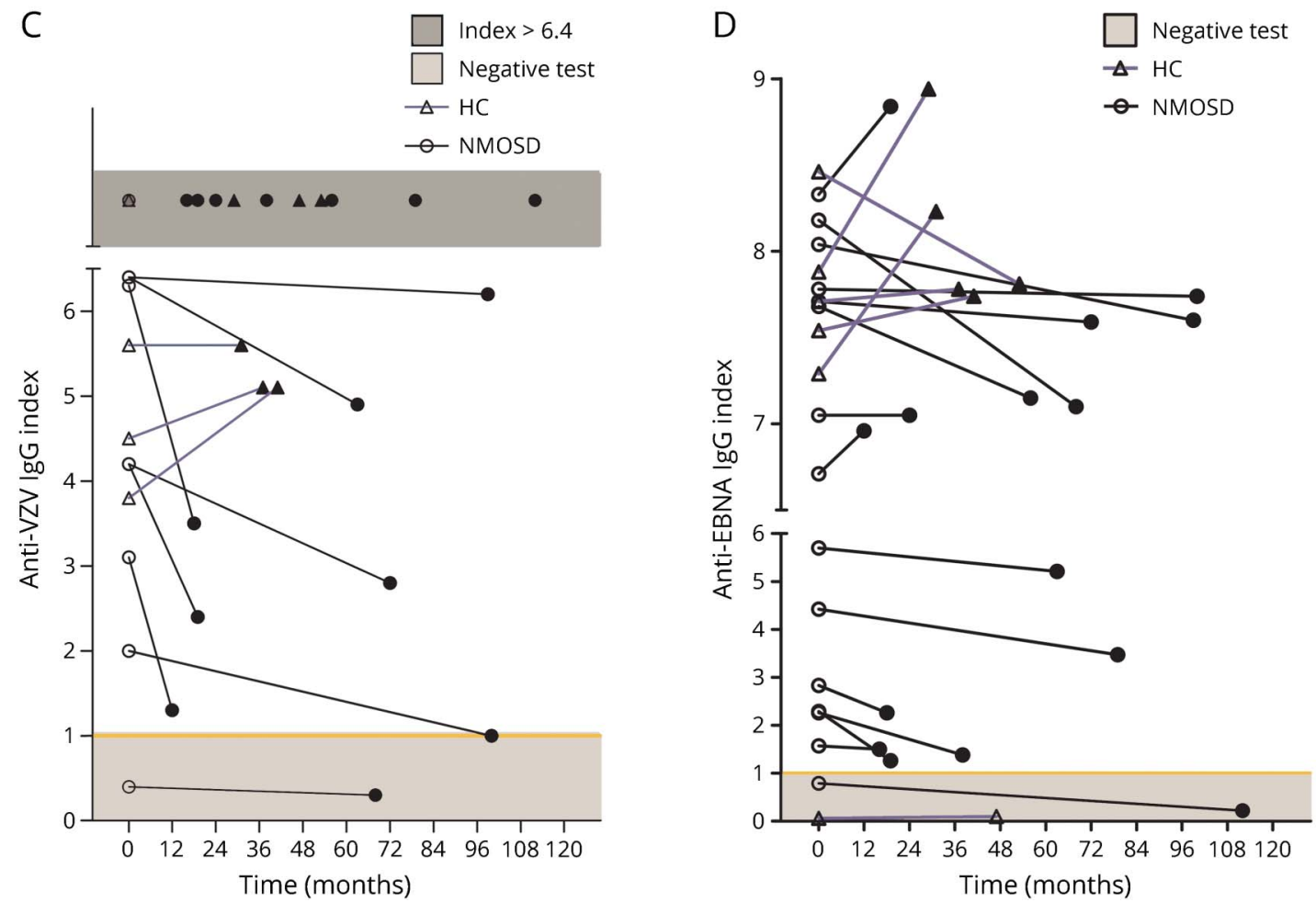

Anti-TET, anti-VZV, and anti-EBNA IgGs were tested in 48 samples from 15 patients with NMOSDs and in 12 samples from 6 HCs. Panels A, C, and D show the over-time variation in the levels of anti-TET IgG, anti-VZV, and anti-EBNA IgG index in patients with NMOSDs (circle, black line) and in HCs (triangle, purple line). The first measurement (open circle or triangle) and the last available measurement (closed circle or triangle) among the entire follow-up period were considered for each subject. Anti-TET IgG showed a reduction in 10/15 patients and in HCs (A). The yellow line shows the threshold of ineffective protection from tetanus (light-gray zone, anti-TET IgG $<0.1 \mathrm{U} / \mathrm{mL}$ ). The levels of anti-TET IgG resulted significantly lower in patients during RTX treatment as compared to HCs (B). Anti-VZV IgG was reduced in 8/15 patients and 0/6 controls (C). The yellow line shows the threshold of negativity status for anti-VZV (light-gray zone, index $\leq 1.0$ ). Seven patients with NMOSDs and $3 \mathrm{HCs}$ showed levels of anti-VZV IgG index upper the limit of detection (index $>6.4$, dark-gray zone).

Notably, all patients demonstrated a depletion of $\mathrm{CD} 19^{+} \mathrm{B}$ cells after each RTX infusion, indicating the biological effectiveness of the drug. No association between the occurrence of hypo- or severe hypo-Ig and baseline Ig values, the number of RTX cycles, and the duration of treatment was found. Finally, no relationship was found between previous immunosuppressive 
treatments and basal hypogammaglobulinemia condition (data not shown). It is important to note that the sample size of our cohort does not allow for adequate statistics to be performed for such analyses.

However, the heterogeneity emerging in this case series study is a motivation to plan further studies on this side effect, given the evidence in literature wherein, in a variable proportion of cases, Ig deficit was further complicated by infections ${ }^{16}$ and could require an Ig-replacement therapy. ${ }^{32,33}$

In our cohort, $3 / 15$ patients showed IgG concentrations below $4 \mathrm{~g} / \mathrm{L}$ during treatment, a level indicative of augmented infectious risk. $^{24,25}$ Similarly, another independent risk factor, i.e. IgM serum concentration $<0.2 \mathrm{~g} / \mathrm{L}$, was found in 2 of our patients. Both these conditions are associated with increased incidence of bacterial infections, especially affecting the airway. ${ }^{25}$ In our cohort, 2 patients (13.3\%) developed severe infectious complications while having hypo-IgG status. Based on the design and intent of the current study, it is not possible to make any conclusive statement regarding the causal relationship between serious infections and RTX/hypo-Ig. However, we do speculate that a relationship might exist between infections and RTX/hypo-Ig as supported by the following evidences: (1) We never observed serious infections in other RTX-treated patients wherein IgG and IgM levels were normal; (2) serious infections have never been reported by the same patients during other treatments before starting RTX; and (3) the prevalence of serious infectious events in our cohort is in line with those reported in the literature. ${ }^{27}$

In addition to total $\operatorname{Ig}(\operatorname{IgG}, \operatorname{IgA}$, and $\operatorname{IgM})$, we investigated several specific IgGs (i.e. anti-AQP4 IgG and anti-pathogen IgGs). In patients with NMOSDs, anti-AQP4 IgG titers have been suggested to be related to biological and clinical response to RTX treatment. ${ }^{34,35}$ Data from this study confirmed our previous findings regarding the reduction of anti-AQP4 IgG titer during long-term RTX treatment ${ }^{23}$ in a bigger cohort of patients (figure 2A). Of interest, in individual analysis, such a reduction was not observed in 2 patients (\#4 and \#5). Both patients showed high anti-AQP4 IgG titers during their entire follow-up period. In particular, patient 4 was considered a clinical nonresponder to RTX and was shifted to tocilizumab after 4 years of treatment and 4 RTX infusions. A correlation was observed between IgG levels and anti-AQP4 IgG titers on excluding these patients with anomalous titers (figure $2 \mathrm{~B}$ ).

The systematic evaluation of the levels of specific antipathogen IgGs during RTX therapy is rare in the literature. Yet, this aspect is of particular interest, given the long-term management of patients with NMOSDs and/or for patients treated with anti-CD20 drugs. The effects of RTX on antiTET IgG were investigated because of previous evidences of specific protection and immunization impairments in RTXtreated patients and the importance of short half-life seroprotection during such a long-term therapy. Anti-VZV and anti-EBNA IgGs levels were also measured to gain novel insights about temporal changes of specific humoral immunity against latent viral pathogens during B-cell depletion.

A reduction in the analyzed anti-pathogen IgG levels was observed more frequently in RTX-treated patients compared with HCs (figure 3). Also, our results highlight anti-TET IgG half-life of 5.52 years (95\% CI: 3.63-10.89), representing a substantial $(50 \%)$ reduction as compared to the estimated $\mathrm{T} 1 / 2$ in the general population. ${ }^{28}$ These patients, therefore, might be at a risk to become unprotected from tetanus unexpectedly and may require additional vaccination. This is of particular interest, given an immunosuppressive therapy, which has been proven to impair the efficacy of active immunization with either recall or new, bacterial or viral antigens. $^{36}$

Given these results, it is important to mention the limitations of the current study. First, this is a retrospective study on a small group of patients. The analysis of specific antipathogen IgGs was restricted to only 3 pathogens. Moreover, it was conducted specifically only on RTX treatment with a "treatment-to-target" approach. RTX maintenance regimen with fixed reinfusion intervals (mainly every 6 months) ${ }^{18}$ could further enhance hypo-Ig risk in comparison with the regimen used in this study (resulting in 11-month reinfusion rate). In fact, data from ocrelizumab phase III trials showed a $16 \%$ hypo-IgM incidence after the first year of treatment. ${ }^{37}$ Our data demonstrate a $7 \%$ incidence at a similar time point.

In spite of these limitations, the present study is based on a high number of measurements, a long follow-up period, and a rigorous selection of samples. Thus, an attempt may be made to provide practical suggestions for neurologists involved in the management of patients with NMOSDs and MS treated with both existing and novel anti-CD20 drugs (table 2).

The concentration of serum Ig should be measured before therapy and at least once a year during treatment. In the present study, we did not observe any sudden reductions in Ig levels throughout the treatment course. Based on our data, annual monitoring provides information regarding the change in Ig concentration over time. Such monitoring could prevent persistent Ig deficiency and would be useful for the prevention of infectious complications as well. Of importance, any decrease in IgG levels below the warning threshold $(4 \mathrm{~g} / \mathrm{L})$ was always preceded by deficient (hypo-IgG) values for more than a year during our study.

Regarding anti-pathogen IgGs, our data strongly suggest measurement of anti-TET IgG before starting RTX and to perform vaccination if necessary. Moreover, anti-TET IgG should be measured at least after 5 years to evaluate any further need to ensure seroprotection (table 2).

Finally, this study highlights the phenomenon of long-term RTX treatment inducing a reduction in specific anti-pathogen 
Table 2 Clinical suggestions for management of patients undergoing anti-CD20 treatment

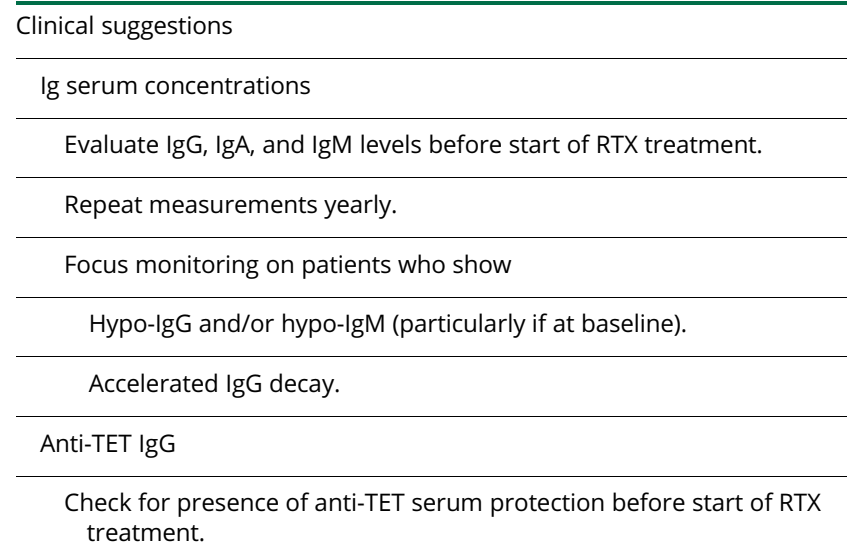

Repeat vaccination in unprotected cases.

Consider revaccination in low-level protected patients $(<1.0 \mathrm{IU} / \mathrm{mL})$ because of accelerated anti-TET IgG decay.

Repeat measurement within 5 years.

Future perspectives

Other specific anti-pathogen IgGs in RTX-treated patients

HBsAb levels: Risk of reactivation of latent HBV infection in RTX-treated patients $^{38}$

Anti-PP IgG: Long-term changes in seroprotection and immunization impairment ${ }^{36}$

Other specific anti-pathogen IgGs in patients with MS

Possible "false negativity" for anti-JCV IgG after RTX treatment.

Possible "false negativity" for anti-VZV IgG after RTX treatment.

Abbreviations: anti-PP = anti-pneumococcal polysaccharide; anti-TET = antitetanus; anti-VZV = varicella-zoster virus; $\mathrm{HBSAB}=$ hepatitis $\mathrm{B}$ surface antibody; HBV = hepatitis B virus; hypo-lg = hypogammaglobulinemia; $\mathrm{Ig}=$ immunoglobulin; RTX = rituximab.

IgGs. Humoral defense against hepatitis B virus and antipneumococcal polysaccharide IgG have been found to be reduced $^{38}$ after RTX treatment, suggesting the need for vigilant monitoring of anti-pathogen IgGs. The reduction in specific anti-pathogen IgGs could be of vital importance when patients with MS treated with RTX or other anti-CD20 drugs are being considered for a shift to fingolimod or natalizumab who require a serologic screening for anti-VZV and anti-JC virus $\mathrm{IgG}$, respectively. ${ }^{39}$

To recapitulate, the present study demonstrates that longterm RTX treatment is associated with the risk of hypo-Ig and reduction in anti-TET protection in patients with NMOSDs. Monitoring total and specific Ig levels before and during treatment with RTX might prevent hypo-Igrelated complications. Further studies involving a larger number of participants are needed to evaluate similar effects of other anti-CD20 drugs used to treat CNS autoimmune disorders to optimize the clinical management of patients.

\section{Author contributions}

A. Bertolotto and F. Marnetto conceived and coordinated the study. F. Marnetto, P. Valentino, A. Balbo, A. Drago and M. Leto collected and processed the samples and performed the laboratory analyses. A. Marcinnò, F. Marnetto, P. Valentino and S. Martire performed acquisition and interpretation of data and wrote the manuscript. S. Martire performed statistical analyses. A. Bertolotto and M. Capobianco were responsible for patient care and clinical documentation. G. Panzica performed a critical revision of the manuscript for intellectual content. All authors read and approved the final version of the manuscript.

\section{Acknowledgment}

The authors thank Euroimmun Italia for providing all the kits (FA 1128-1010-50) for anti-AQP4 IgG titration; Dr. Ishira Nanavaty (freelance editor) for the English revision of the manuscript; Dr. Federica Brescia (Neuroscience Institute Cavalieri Ottolenghi- NICO, Orbassano, Turin, Italy) for technical support in anti-AQP4 IgG titrations; and Dr. Marzia Caldano (Neuroscience Institute Cavalieri Ottolenghi-NICO, Orbassano, Turin, Italy) for selection of samples from the CRESM Collection.

\section{Study funding}

This study was supported by Fondazione Italiana Sclerosi Multipla, FISM (2014/PMS/1), Fondazione per la Ricerca Biomedica Onlus, and by Ministero dell'Istruzione, dell'Università e della Ricerca-MIUR project "Dipartimenti di Eccellenza 2018-2022" to Department of Neuroscience "Rita Levi Montalcini."

\section{Disclosure}

A. Marcinnò received travel funding from Mylan and F. Hoffmann-La Roche and received research support from the University of Turin; F. Marnetto received speaker honoraria form Biogen, Merck Serono, and Euroimmun and received research support from Fondazione Italiana Sclerosi Multipla; P. Valentino received speaker honoraria from Biogen, Merck Serono, and Novartis and received a travel grant from Euroimmun; S. Martire received speaker honoraria from Biogen; A. Balbo, A. Drago, and M. Leto report no disclosures; M. Capobianco served on the scientific advisory board of Biogen, Sanofi Genzyme, Novartis, and Bayer Schering and received speaker honoraria from Almirall, Biogen, Novartis, Sanofi Genzyme, and Teva; G. Panzica served as an associate review editor for Frontiers in Endocrinology, is on the editorial board of Biology of Sex Differences and Cell and Tissue Research, and received research support from the University of Torino; A. Bertolotto served on the scientific advisory board of Almirall, Bayer, Biogen, and Genzyme, received travel funding and/or speaker honoraria from Biogen, Genzyme, Novartis, Sanofi-Aventis, and Teva, served on the editorial board of Multiple Sclerosis International, Progress in Neuroscience, Dataset Papers in Neuroscience, Journal of Multiple Sclerosis, Neurology and Therapy, and Multiple Sclerosis and 
Demyelinating Disorders, and received research support from Merck Serono Italy, Biogen, Euroimmun, the Italian Ministry of Health, the Italian Multiple Sclerosis Foundation, the Ricerca Biomedica ONLUS Foundation, and San Luigi ONLUS. Full disclosure form information provided by the authors is available with the full text of this article at Neurology.org/NN.

Received March 26, 2018. Accepted in final form July 20, 2018.

\section{References}

1. Smolewski P, Robak T. The preclinical discovery of rituximab for the treatment of non-Hodgkin's lymphoma. Expert Opin Drug Discov 2015;10:791-808.

2. Seyfizadeh N, Seyfizadeh N, Hasenkamp J, Huerta-Yepez S. A molecular perspective on rituximab: a monoclonal antibody for B cell non Hodgkin lymphoma and other affections. Crit Rev Oncol Hematol 2016;97:275-290.

3. Maloney DG, Grillo-lo AJ, White CA, et al. IDEC-C2B8 (rituximab) anti-CD20 monoclonal antibody therapy in patients with relapsed low-Grade non-Hodgkin's lymphoma. Blood 1997;90:2188-2195.

4. Edwards JCW, Szczepański L, Szechiński J, et al. Efficacy of B-Cell-Targeted therapy with rituximab in patients with rheumatoid arthritis. N Engl J Med 2004;350: 2572-2581.

5. Edwards JC, Cambridge G. Sustained improvement in rheumatoid arthritis following a protocol designed to deplete B lymphocytes. Rheumatology (Oxford) 2001;40: 205-211.

6. Cohen SB, Emery P, Greenwald MW, et al. Rituximab for rheumatoid arthritis refractory to anti-tumor necrosis factor therapy: results of a multicenter, randomized, double-blind, placebo-controlled, phase III trial evaluating primary efficacy and safety at twenty-four weeks. Arthritis Rheum 2006;54:2793-2806.

7. Jones RB, Furuta S, Tervaert JW, et al. Rituximab versus cyclophosphamide in ANCAassociated renal vasculitis: 2-year results of a randomised trial. Ann Rheum Dis 2015; $74: 1178-1182$.

8. Shah S, Geetha D. Place in therapy of rituximab in the treatment of granulomatosis with polyangiitis and microscopic polyangiitis. Immunotargets Ther 2015;4:173-183.

9. Rath E, Zwerina J, Oppl B, Nell-Duxneuner V. Efficacy and safety of rituximab in rheumatic diseases. Wiener Medizinische Wochenschrift 2015;165:28-35.

10. Damato V, Evoli A, Iorio R. Efficacy and safety of rituximab therapy in neuromyelitis optica spectrum disorders a systematic review and meta-analysis. 2016;73:1342-1348.

11. Etemadifar M, Salari M, Mirmosayyeb O, et al. Efficacy and safety of rituximab in neuromyelitis optica: review of evidence. J Res Med Sci 2017;22:18.

12. Crout TM, Parks LP, Majithia V. Neuromyelitis optica (Devic's syndrome): an appraisal. Curr Rheumatol Rep 2016;18:54.

13. Wingerchuk DM, Banwell B, Bennett JL, et al. International consensus diagnostic criteria for neuromyelitis optica spectrum disorders. Neurology 2015;85:177-189.

14. Besada E, Koldingsnes W, Nossent JC. Serum immunoglobulin levels and risk factors for hypogammaglobulinaemia during long-term maintenance therapy with rituximab in patients with granulomatosis with polyangiitis. Rheumatology (Oxford) 2014;53: 1818-1824.

15. De La Torre I, Leandro MJ, Valor L, Becerra E, Edwards JCW, Cambridge G. Total serum immunoglobulin levels in patients with RA after multiple B-cell depletion cycles based on rituximab: relationship with B-cell kinetics. Rheumatology 2012;51: 833-840.

16. Van Vollenhoven RF, Fleischmann RM, Furst DE, Lacey S, Lehane PB. Long-term safety of rituximab: final report of the rheumatoid arthritis global clinical trial program over 11 years. J Rheumatol 2015;42:1761-1766.
17. Tallantyre EC, Whittam DH, Jolles S, et al. Secondary antibody deficiency: a complication of anti-CD20 therapy for neuroinflammation. J Neurol 2018;265: $1115-1122$.

18. Gelfand JM, Cree BAC, Hauser SL. Ocrelizumab and other CD20+ B-cell-depleting therapies in multiple sclerosis. Neurotherapeutics 2017;14:835-841.

19. Martinez-Hernandez E, Sepulveda M, Rostásy K, et al. Antibodies to aquaporin 4 myelin-oligodendrocyte glycoprotein, and the glycine receptor $\alpha 1$ subunit in patients with isolated optic neuritis. JAMA Neurol 2015;72:187-193.

20. Chang $\mathrm{KH}$, Lyu RK, Chen CM, et al. Distinct features between longitudinally extensive transverse myelitis presenting with and without anti-aquaporin 4 antibodies. Mult Scler J 2013;19:299-307.

21. Kitley J, Leite MI, Küker W, et al. Longitudinally extensive transverse myelitis with and without aquaporin 4 antibodies. JAMA Neurol 2013;70:1375-1381.

22. Jarius S, Ruprecht K, Wildemann B, et al. Contrasting disease patterns in seropositive and seronegative neuromyelitis optica: a multicentre study of 175 patients. J Neuroinflammation 2012;9:14.

23. Valentino P, Marnetto F, Granieri L, Capobianco M, Bertolotto A. Aquaporin-4 antibody titration in NMO patients treated with rituximab. Neurol Neuroimmunol Neuroinflammation 2017;4:e317. doi: 10.1212/NXI.0000000000000317.

24. Furst DE. Serum immunoglobulins and risk of infection: how low can you go? Semin Arthritis Rheum 2009;39:18-29.

25. Blot M, Boyer P, Samson M, et al. Should mild hypogammaglobulinemia be managed as severe hypogammaglobulinemia? A study of 389 patients with secondary hypogammaglobulinemia. Eur J Intern Med 2014;25:837-842.

26. Franciotta D, Gastaldi M, Sala A, et al. Diagnostics of the neuromyelitis optica spectrum disorders (NMOSD). Neurol Sci 2017;38:231-236.

27. Granieri L, Marnetto F, Valentino P, et al. Evaluation of a multiparametric immunofluorescence assay for standardization of neuromyelitis optica serology. PLoS One 2012;7:1-9.

28. Amanna IJ, Carlson NE, Slifka MK. Duration of humoral immunity to common viral and vaccine antigens. N Engl J Med 2007;357:1903-1915.

29. Kantele J, Kantele A, Arvilommi H. Circulating immunoglobulin-secreting cells are heterogeneous in their expression of maturation markers and homing receptors. Clin Exp Immunol 1996;104:525-530.

30. Tangye SG, Avery DT, Hodgkin PD. A division-linked mechanism for the rapid generation of Ig-secreting cells from human memory B cells. J Immunol 2003;170: 261-269.

31. Bernasconi NL, Traggiai E, Lanzavecchia A. Maintenance of serological memory by polyclonal activation of human memory B cells. Science 2002;298:2199-2202.

32. Marco H, Smith RM, Jones RB, et al. The effect of rituximab therapy on immunoglobulin levels in patients with multisystem autoimmune disease. BMC Musculoskelet Disord 2014;15:178.

33. Smolen JS, Landewé R, Bijlsma J, et al. EULAR recommendations for the management of rheumatoid arthritis with synthetic and biological disease-modifying antirheumatic drugs: 2016 update. Ann Rheum Dis 2017;76:960-977.

34. Jarius S, Franciotta D, Paul F, et al. Testing for antibodies to human aquaporin-4 by ELISA: sensitivity, specificity, and direct comparison with immunohistochemistry. J Neurol Sci 2012;320:32-37.

35. Kim W, Lee J-E, Li XF, et al. Quantitative measurement of anti-aquaporin-4 antibodies by enzyme-linked immunosorbent assay using purified recombinant human aquaporin-4. Mult Scler J 2012;18:578-586.

36. Kado R, Sanders G, McCune WJ. Suppression of normal immune responses after treatment with rituximab. Curr Opin Rheumatol 2016;28:251-258.

37. Frampton EJ. Ocrelizumab: first global approval. Drugs 2017;77:1035-1041.

38. Kusumoto S, Tanaka Y, Ueda R, Mizokami M. Reactivation of hepatitis B virus following rituximab-plus-steroid combination chemotherapy. J Gastroenterol 2011; 46:9-16.

39. Cross AH, Naismith RT. Established and novel disease-modifying treatments in multiple sclerosis. J Intern Med 2014;275:350-363. 


\section{Neurology \\ Neuroimmunology \& Neuroinflammation}

\section{Rituximab-induced hypogammaglobulinemia in patients with neuromyelitis optica spectrum disorders \\ Andrea Marcinnò, Fabiana Marnetto, Paola Valentino, et al. \\ Neurol Neuroimmunol Neuroinflamm 2018;5; \\ DOI 10.1212/NXI.0000000000000498}

This information is current as of September 14, 2018

\section{Updated Information \& \\ Services}

References

Citations

Subspecialty Collections

Permissions \& Licensing

Reprints including high resolution figures, can be found at:

http://nn.neurology.org/content/5/6/e498.full.html

This article cites 38 articles, 7 of which you can access for free at: http://nn.neurology.org/content/5/6/e498.full.html\#\#ref-list-1

This article has been cited by 8 HighWire-hosted articles: http://nn.neurology.org/content/5/6/e498.full.html\#\#otherarticles

This article, along with others on similar topics, appears in the following collection(s):

Autoimmune diseases

http://nn.neurology.org//cgi/collection/autoimmune_diseases

Information about reproducing this article in parts (figures,tables) or in its entirety can be found online at:

http://nn.neurology.org/misc/about.xhtml\#permissions

Information about ordering reprints can be found online:

http://nn.neurology.org/misc/addir.xhtml\#reprintsus

Neurol Neuroimmunol Neuroinflamm is an official journal of the American Academy of Neurology.

Published since April 2014, it is an open-access, online-only, continuous publication journal. Copyright

Copyright $\odot 2018$ The Author(s). Published by Wolters Kluwer Health, Inc. on behalf of the American

Academy of Neurology.. All rights reserved. Online ISSN: 2332-7812.

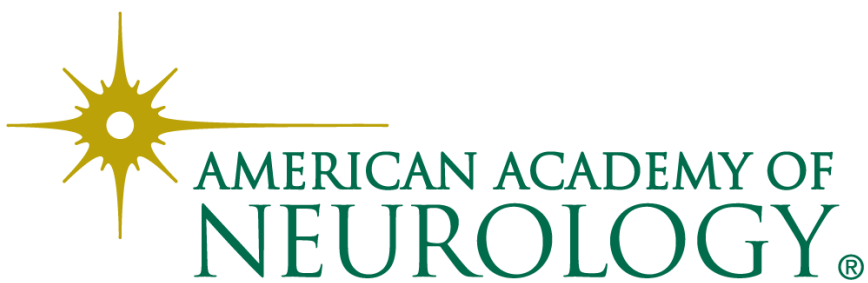

